\title{
Contribution of aspiration to the diagnosis of lung cancer in endobronchial ultrasound-guided fine-needle biopsy
}

\author{
Arzu Nakıs Guven ${ }^{1}$, Murat Yalcinsoy ${ }^{1 *}$ (D) Ayse Nur Akatlı² (D), Ahmet Kadir Arslan³
}

\begin{abstract}
SUMMARY
OBJECTIVE: Endobronchial ultrasound-guided transbronchial needle aspiration has been successfully applied in both diagnosis and staging of mediastinal and hilar lymphadenopathies and masses, especially in malignant cases. However, the optimal procedure of Endobronchial ultrasound-guided transbronchial needle aspiration to further increase diagnostic yield and minimize processing complexity remains controversial. This study aims to compare aspiration biopsy (Endobronchial ultrasound-guided transbronchial needle aspiration) and non-aspiration biopsy (Endobronchial ultrasound-guided transbronchial needle capillary sampling) in terms of sample adequacy, diagnosis, and quality in malignant cases.

METHODS: Between March 2018 and June 2020, Endobronchial ultrasound-guided was performed sequentially on patients with mediastinal and/or hilar lymph nodes that were considered malignant. Each lymphadenopathy was sampled with and without aspiration. A single-blinded pathologist evaluated the samples.

RESULTS: A total of 84 lymph nodes evaluations of 51 patients were included. Most samples were taken from the right lower paratracheal lymph nodes $(n=27,32.2 \%)$ and subcarinal $L N(n=21,25 \%)$. The mean size of the lymph nodes was $21.21 \pm 8.257(8-40) \mathrm{mm}$. The agreement between the two procedures in terms of sample adequacy and diagnostic yield was $69.1 \%(95 \% \mathrm{Cl} 58-78.7, \mathrm{p}=0.076)$. In addition, according to the goodness-of-fit statistics, the kappa values were 0.255 ( $p=0.015)$ and 0.302 ( $p=0.004)$ for sample adequacy and diagnostic yield, respectively. There was no difference between the two procedures in relation to complications.

CONCLUSION: Although the agreement between the two procedures is weak, Endobronchial ultrasound-guided transbronchial needle capillary sampling can be performed with less personnel, without reducing diagnostic yield and tissue adequacy. These findings can assist clinicians in determining the optimal procedure for Endobronchial ultrasound-guided.

KEYWORDS: Lung cancer. Fine needle biopsy. Bronchoscopy. Lymph node biopsy, sentinel.
\end{abstract}

\section{INTRODUCTION}

Clinical studies have shown that endobronchial ultrasound-guided transbronchial needle aspiration (EBUS-TBNA) is similar to or even better than surgical mediastinoscopy in the diagnosis of mediastinal and hilar lymphadenopathies, possibly due to its low cost and safe diagnostic technology ${ }^{1}$. EBUS-TBNA has gained more importance since it was adopted for use in staging, especially in malignant cases. In the traditional EBUS-TBNA procedure, aspiration is applied following the removal of the metal stylet from the inner lumen of the needle after entering

\footnotetext{
'Inonu University, Medical Faculty, Turgut Ozal Medical Center, Department of Pulmonary Medicine - Malatya, Turkey.

IInonu University, Medical Faculty, Turgut Ozal Medical Center, Department of Pathology - Malatya, Turkey.

${ }^{3}$ Inonu University, Department of Biostatistics - Malatya, Turkey.

*Corresponding author: mrtyalcinsoy@yahoo.com

Conflicts of interest: the authors declare there is no conflicts of interest. Funding: This study was financially supported by the BAP unit of Inonu University (2015/45).

Received on September 20, 2021. Accepted on September 21, 2021.
} 
the lesion. Nevertheless, the optimal procedure of EBUS-TBNA remains controversial ${ }^{2-4}$. Fine-needle sampling without the use of aspiration, i.e., capillary sampling, has been investigated in various tissues (e.g., breast, thyroid, and peripheral lymph nodes [LNs]) and shown to have similar diagnostic yield and cause less trauma compared to fine-needle aspiration ${ }^{5,6}$. However, the use of EBUS-guided needle capillary sampling (EBUS-TBNCS) has been described only in a limited number of studies ${ }^{7-11}$.

Since there is considerable debate whether aspiration is required during EBUS-TBNA, we conducted a prospective, randomized controlled study to determine the optimal EBUSTBNA procedure for detecting mediastinal and hilar lymphadenopathies in malignant cases. In this study, we aimed to compare the EBUS-TBNA and EBUS-TBNCS procedures in terms of sample adequacy, diagnosis, and quality in malignant mediastinal and hilar LNs.

\section{METHODS}

The study was carried out between March 2018 and June 2020 at the Department of Chest Diseases of Inonu University Turgut Özal Medical Center. Approval was obtained from the interventional ethics committee of the university for this prospective, randomized, interventional, single-blind study (approval number: 2018/107). Detailed information was given to the patients before the procedure, and all signed a consent form.

\section{Patient population}

All patients who presented to our clinic with a mediastinal mass, mediastinal LN, or parenchymal mass invading the mediastinum and who were considered to be clinically and radiologically malignant underwent EBUS sequentially. Exclusion criteria included age $<18$ years, exclusions for EBUS-TBNA (uncontrolled coagulopathy or bleeding diathesis, clinical stability), benign pathological results, and non-informed consent.

\section{Study design}

The volunteers' demographic data (age, gender, and comorbidities), anamnesis, smoking history, results of computed tomography (CT), results of positron emission tomography (PET)-CT if undertaken, complications that developed during the procedure, the number of LNs sampled, and pathological results were documented. The biopsy procedure was performed from the same lesion under the same conditions with and without aspiration. To prevent the first pass effect, biopsies with and without aspiration were performed in each LN in a different order. The samples were coded with numbers. The researcher was the only person who had knowledge of the code of each sample. The pathologist was not provided this information to ensure that the study was conducted in a single-blinded manner (Figure 1).

Imaging was performed with a fiberoptic bronchoscope (Fujinon Fujifilm Ultrasonic Processor SU-1), and samples were taken. A 22G fenestrated needle (Cook Medical, USA) was used as the aspiration needle.

To summarize the technique, during the procedure, before the bronchoscope and catheter needle were removed from their sheath, they were directed to the targeted point, and the metal tip of the catheter was allowed to contact the mucosa. In this position, the needle was inserted quickly and hard. The penetration of the needle through the wall along its entire length was checked with an ultrasound image. For this purpose, the bronchoscope was pushed through the catheter and advanced toward the bronchial wall. When the needle was in the targeted place, the artifacts were removed with the stylet. Both methods were the same up to this point. Then, the stylet was removed and aspirated with negative pressure using a $10-\mathrm{mL}$ injector for aspiration method. In the non-aspirated biopsy method, after using a stylet to remove the artifacts from the needle, the stylet was pulled back by $10 \mathrm{~cm}$ and the needle was advanced back and forth inside the LN without aspiration, and the biopsy sample was obtained. In both methods, the back-andforth movements were performed in the LN for 25-30 times.

\section{Statistical analysis}

The variables used in analyses were summarized as number (percentage) and mean \pm standard deviation/median (min-max) values according to their qualitative and quantitative nature. Fisher's exact and chi-square tests were used to determine the statistically significance/relationship between the groups of qualitative variables. The significance of differences between the non-aspirated and aspirated biopsy methods was analyzed using the McNemar-Bowker test. The degree of agreement between these two methods was evaluated using the kappa statistics. In addition, the diagnostic performance of the reference test was measured based on accuracy, sensitivity, and selectivity among the diagnostic test criteria. A $\mathrm{p}<0.05$ was accepted as the level of significance. IBM SPSS Statistics version 26.0 was used to perform statistical analyses.

\section{RESULTS}

A total of $84 \mathrm{LN}$ evaluations of 51 patients were included in the study. The demographic data of the patients and biopsied LNs are summarized in Table 1. Notably, 11 (21.6\%) patients were females and $40(78.4 \%)$ were males.

Two LN aspirations were performed in most of the patients. The number of LN aspirations performed was 2 of 27,1 of 21 , 


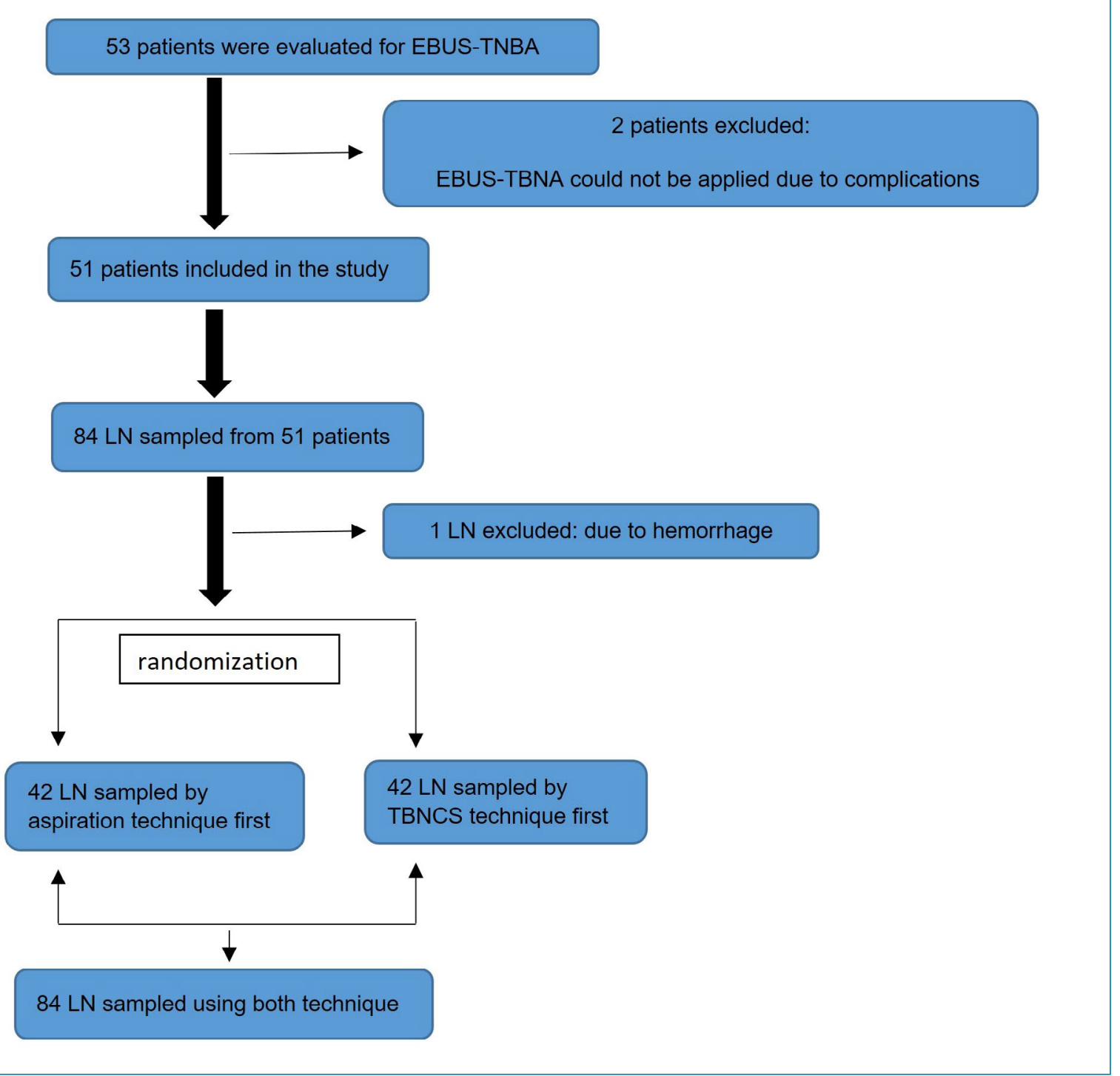

Figure 1. EBUS-TBNA: endobronchial ultrasound-guided transbronchial needle aspiration; LN: Iymph node; TBNCS: transbronchial needle capillary sampling. Study flowchart of enrolled patients.

and 3 of 3 patients. Aspiration biopsies were mostly performed from the right lower paratracheal $\mathrm{LN}(\mathrm{n}=27,32.2 \%)$, followed by subcarinal $\mathrm{LN}(\mathrm{n}=21,25 \%)$ and left and right lobar $\mathrm{LNs}$ $(\mathrm{n}=2,2.4 \%$ and $\mathrm{n}=4,4.8 \%$, respectively). The mean size of the LNs was $21.21 \pm 8.257(8-40) \mathrm{mm}$.

\section{Agreement on sample adequacy and diagnostic yield}

The agreement between the EBUS-TBNA and EBUS-TBNCS procedures was high, with no significant difference in the sample yield. The agreement rate for sample adequacy was $69.1 \%$ (95\%CI, 58-78.7, $\mathrm{p}=0.076)$. In addition, according to the goodness-of-fit statistics, the kappa value was 0.255 ( $\mathrm{p}=0.015)$. The agreement rate for diagnostic yield was $69.1 \%$ (95\%CI, $58-78.7, \mathrm{p}=0.076$ ). The kappa value for diagnostic yield was $0.302(\mathrm{p}=0.004)$ (Table 2).

Considering the subtypes of the pathological diagnoses, squamous cell carcinoma was present in $19(37.2 \%)$ patients, small cell lung carcinoma in 14 (27.4\%), adenocarcinoma in 13 (25.4), and leukemia, lymphoma, and metastasis in $1(2 \%)$. One (2\%) patient was suspected for malignancy, and in 1 of 2 patients who could not be subtyped by EBUS, the postoperative histology was reported as small cell lung cancer, and the final results were unknown since the other patient did not 
Table 1. Demographic data and characteristics of biopsied lymph nodes.

\begin{tabular}{|c|c|}
\hline & $\mathrm{n}(\%)$ \\
\hline Age (mean), years & $61.6 \pm 10.3$ \\
\hline \multicolumn{2}{|l|}{ Gender } \\
\hline Female & $11(21.6)$ \\
\hline Male & $40(78.4)$ \\
\hline \multicolumn{2}{|l|}{ Smoking status } \\
\hline Active smoker & $20(39.2)$ \\
\hline Tobacco-naive & $15(29.4)$ \\
\hline Former smoker & $16(31.4)$ \\
\hline \multicolumn{2}{|l|}{ Referring department } \\
\hline Neurosurgery & $3(5.9)$ \\
\hline Internal diseases & $1(2.0)$ \\
\hline Thoracic surgery & $4(7.8)$ \\
\hline Chest diseases & $39(76.5)$ \\
\hline Gynecology & $1(2.0)$ \\
\hline Cardiology & $1(2.0)$ \\
\hline Oncology & $2(3.9)$ \\
\hline \multicolumn{2}{|l|}{ Comorbidities } \\
\hline Hypertension & $9(17.6)$ \\
\hline Diabetes mellitus & $7(13.7)$ \\
\hline Coronary artery disease & $8(15.6)$ \\
\hline Malignancy & $3(5.8)$ \\
\hline Chronic obstructive pulmonary disease & $3(5.8)$ \\
\hline Asthma & $1(2.0)$ \\
\hline Hypothyroidism & $1(2.0)$ \\
\hline \multicolumn{2}{|l|}{ Complications } \\
\hline Minimal hemorrhage & $6(11.8)$ \\
\hline Desaturation & $3(5.9)$ \\
\hline Hypertension & $1(2.0)$ \\
\hline Desaturation and minimal hemorrhage & $1(2.0)$ \\
\hline \multicolumn{2}{|l|}{ Biopsied lymph nodes } \\
\hline Lymph node size, mm & 84 \\
\hline Lymph nodes by location & $21.21 \pm 8.257$ \\
\hline $4 \mathrm{~L}$ & $9(10.7)$ \\
\hline $4 R$ & $27(32.1)$ \\
\hline 7 & $21(25)$ \\
\hline $10 \mathrm{~L}$ & $2(2.4)$ \\
\hline $10 R$ & $6(7.1)$ \\
\hline $11 \mathrm{~L}$ & $6(7.1)$ \\
\hline $11 R$ & $7(8.3)$ \\
\hline $12 \mathrm{~L}$ & $2(2.4)$ \\
\hline $12 \mathrm{R}$ & $4(4.8)$ \\
\hline \multicolumn{2}{|l|}{ Malignancy subtype } \\
\hline Squamous cell lung carcinoma & $19(37.2)$ \\
\hline Small cell lung carcinoma & $14(27.4)$ \\
\hline Lung adenocarcinoma & $13(25.4)$ \\
\hline Large cell lung carcinoma & $2(2.0)$ \\
\hline Leukemia & $2(2.0)$ \\
\hline Lymphoma & $2(2.0)$ \\
\hline Metastasis & $2(2.0)$ \\
\hline Suspicious for malignancy & $2(2.0)$ \\
\hline
\end{tabular}

present to our center again and could not be reached by phone. The operation result of the patient who had been diagnosed with non-small cell lung carcinoma was reported as large cell lung carcinoma.

There were no life-threatening complications among the EBUS patients. While minimal complications were observed in $11(21.6 \%)$ patients, no complication developed in 40 (78.4\%) patients. In two patients, due to hypertension and desaturation before the procedure, the procedure could not be initiated. The data of these patients were not included in the study statistics. A further patient had severe hemorrhage during the procedure; thus, after aspiration biopsy, the procedure was terminated without performing non-aspiration biopsy. The hemorrhage was controlled with cold saline solution, and no other complication occurred. The result of the aspiration biopsy of this patient was consistent with vasculitis, and the patient was excluded from the study. A total of $11(21.6 \%)$ patients had minimal complications that did not require the termination of the procedure (Table 3). Minimal complications seen were desaturation $(n=3,5.9 \%)$, hypertension $(n=1,2 \%)$, minimal hemorrhage $(n=6,11.8 \%)$, and desaturation and hemorrhage $(\mathrm{n}=1,2 \%)$.

Although there were no serious and mortal complications in the patients, the relationship between minimal complications and comorbidities was evaluated, and there was no significant relationship ( $>0.05)$ (Table 3).

\section{DISCUSSION}

Our study showed weak agreement between conventional aspiration biopsy performed by EBUS-TBNA and capillary biopsy (EBUS-TBNCS) in terms of cytological sample adequacy of malignant LNs and diagnostic yield in patients with lung cancer. A capillary biopsy can be preferred in the EBUS procedure undertaken in malignant cases since it has similar sample adequacy, low risk of bleeding, and a short procedure time although the last parameter was not evaluated in our study. Although more data and further studies are needed, our findings may be a guide for physicians performing interventional procedures in determining the optimal EBUS-TBNA biopsy procedure.

Since first described by Paget in 1853 (on a breast tumor), fine-needle aspiration has been widely used ${ }^{12}$. However, over time, the role of aspiration in fine-needle biopsy has been discussed. Zajdela et al. retrospectively compared 635 capillary sampling and 7,877 fine-needle aspiration in breast tumors and found no difference in diagnostic yield or cellularity, and reported less blood in samples obtained without aspiration ${ }^{13}$. Mair et al. found no difference in diagnostic yield between conventional fine-needle aspiration and fine-needle capillary 
Table 2. Agreement between EBUS-TBNA and EBUS-TBNCS in terms of sample adequacy and diagnostic yield for the biopsied lymph nodes $(n=84)$.

\begin{tabular}{|c|c|c|c|c|}
\hline & & EBUS & & \\
\hline \multirow{6}{*}{ EBUS-TBNCS } & Sample adequacy (\%) & Negative & Positive & Agreement $(95 \% \mathrm{Cl})$ \\
\hline & Negative & $11(14)$ & $18(21)$ & \multirow{5}{*}{$69.1(58-78.6)$} \\
\hline & Positive & $8(9)$ & $47(56)$ & \\
\hline & \multicolumn{3}{|c|}{ Diagnostic yield (\%) } & \\
\hline & Negative & $14(17)$ & $18(21)$ & \\
\hline & Positive & $8(10)$ & $44(52)$ & \\
\hline
\end{tabular}

EBUS-TBNA: endobronchial ultrasound-guided transbronchial needle aspiration; EBUS-TBNCS: endobronchial ultrasound-guided needle capillary sampling; Cl: confidence interval.

Table 3. Relationship between complications during the procedure and comorbidities of the patients.

\begin{tabular}{|c|c|c|c|c|c|}
\hline & & \multicolumn{2}{|c|}{ Complication } & \multirow{2}{*}{ Total, n (\%) } & \multirow{2}{*}{ p-value* } \\
\hline & & Absent, $n(\%)$ & Present, $\mathrm{n}(\%)$ & & \\
\hline \multirow{3}{*}{ Hypertension } & Absent & $33(82.50)$ & $9(81.82)$ & $42(82.35)$ & \multirow{3}{*}{0.999} \\
\hline & Present & $7(17.50)$ & $2(18.18)$ & $9(17.65)$ & \\
\hline & Total & $40(100.00)$ & $11(100.00)$ & $51(100.00)$ & \\
\hline \multirow{3}{*}{ Diabetes mellitus } & Absent & $34(85.00)$ & $10(90.91)$ & $44(86.27)$ & \multirow{3}{*}{0.999} \\
\hline & Present & $6(15.00)$ & $1(9.09)$ & $7(13.73)$ & \\
\hline & Total & $40(100.00)$ & $11(100.00)$ & $51(100.00)$ & \\
\hline \multirow{3}{*}{$C A D$} & Absent & $33(82.50)$ & $10(90.91)$ & $43(84.31)$ & \multirow{3}{*}{0.668} \\
\hline & Present & $7(17.50)$ & $1(9.09)$ & $8(15.69)$ & \\
\hline & Total & $40(100.00)$ & $11(100.00)$ & $51(100.00)$ & \\
\hline \multirow{3}{*}{ COPD } & Absent & $38(95.00)$ & $10(90.91)$ & $48(94.12)$ & \multirow{3}{*}{0.526} \\
\hline & Present & $2(5.00)$ & $1(9.09)$ & $3(5.88)$ & \\
\hline & Total & $40(100.00)$ & $11(100.00)$ & $51(100.00)$ & \\
\hline \multirow{3}{*}{ Malignancy } & Absent & $37(92.50)$ & $11(100.00)$ & $48(94.12)$ & \multirow{3}{*}{0.999} \\
\hline & Present & $3(7.50)$ & $0(0.00)$ & $3(5.88)$ & \\
\hline & Total & $40(100.00)$ & $11(100.00)$ & $51(100.00)$ & \\
\hline \multirow{3}{*}{ Asthma } & Absent & $39(97.50)$ & $11(100.00)$ & $50(98.04)$ & \multirow{3}{*}{0.999} \\
\hline & Present & $1(2.50)$ & $0(0.00)$ & $1(1.96)$ & \\
\hline & Total & $40(100.00)$ & $11(100.00)$ & $51(100.00)$ & \\
\hline \multirow{3}{*}{ Hypothyroidism } & Absent & $39(97.50)$ & $11(100.00)$ & $50(98.00)$ & \multirow{3}{*}{0.999} \\
\hline & Present & $1(2.50)$ & $0(0.00)$ & $1(2.00)$ & \\
\hline & Total & $40(100.00)$ & $11(100.00)$ & $51(100.00)$ & \\
\hline
\end{tabular}

CAD: coronary artery disease; COPD: chronic obstructive pulmonary disease. *Fisher's exact test.

sampling in a study of 100 superficial masses in various body regions, and they also showed that the samples obtained using capillary sampling had better quality ${ }^{6}$. In our study, although there was a weak agreement rate between EBUS-TBNA and EBUS-TBNCS, the latter did not yield samples of superior quality compared to the aspiration method. In a recent prospective EBUS study conducted with 66 patients, Boonsarngsuk et al. compared three different aspiration pressure levels ( 0 [no suction], -20 , and $-40 \mathrm{~cm} \mathrm{H}_{2} \mathrm{O}$ ) and determined that the diagnostic value of biopsies performed without aspiration was lower $\left(63.6,75.8\right.$, and $83.3 \%$, respectively) ${ }^{7}$. Casal et al., prospectively comparing biopsies with and without aspiration in 115 patients with a total of $192 \mathrm{LNs}$, reported no difference between sample quality and diagnosis rate and noted that there 
was a high agreement between the two methods'. Similarly, in a prospective study of 38 patients, Rodriguez et al. found a high agreement between aspiration and non-aspiration biopsies (sample adequacy: $95.5 \%$; diagnosis specificity: $84 \%)^{8}$. Harris et al. compared the same two methods in a prospective non-inferiority study of 24 patients and observed no difference ${ }^{14}$. Although there was weak agreement in our study, as the authors, we think that TBNCS can be used because of its ease of procedure, less personnel requirement, time saving, and no complications.

Complications in EBUS-TBNA are extremely rare. The most common complication is bleeding, and other rare complications include infection, pneumothorax, and device or needle damage. In a study undertaken by the Japan Respiratory Endoscopy Society covering a total of 7,345 cases reported from 210 centers, the complication rate was only $1.23 \%$. The most common complication was bleeding ( $\mathrm{n}=50)$, followed by infection $(\mathrm{n}=14)$, ultrasound bronchoscope damage $(\mathrm{n}=98)$, and needle damage $(\mathrm{n}=15)^{15}$. Similarly, another systematic review of adverse events in 16,181 patients undergoing endosonography for mediastinal and hilar LNs or central lung masses reported only $23(0.14 \%)$ serious adverse events without mortality ${ }^{16}$. In our study, in one patient, due to severe hemorrhage during the procedure, after aspiration biopsy, the procedure was terminated without performing non-aspiration biopsy. Our study showed that in accordance with the literature, EBUS-TBNA is a generally safe method, and different EBUS-TBNA procedures have a similar probability of complications.

The main limitations of our study are that it was conducted in a single center and there was a single operator. A multicenter study would provide better data to confirm the statistical significance of the results obtained using different EBUS-TBNA procedures. Another limitation may be related to the number of times the needle was moved within the LN. Although there is no evidence for the ideal number, it can be argued that this number of back-and-forth movements was high, which could have led to more bloody samples. In addition, one needle was used for each patient, and different needles were not used for different methods in the same patient. Using a separate needle for each $\mathrm{LN}$ in the same patient and different needles for the two methods may have been ideal to prevent contamination; however, we were not able to do this due to financial reasons. However, to minimize the risk of contamination and provide randomization, we changed the order of methods performed in our patients.

\section{CONCLUSIONS}

EBUS-TBNA requires the manual aspiration of lock-mechanism syringe or additional personnel to perform aspiration during biopsy. This requirement can be eliminated with the use of the EBUS-TBNCS technique. According to the results of our study, we recommend EBUS-TBNCS technique as a simpler and equally effective technique for EBUS-guided biopsies of mediastinal and hilar LNs in the diagnosis of patients with suspected malignancy.

\section{AUTHORS" CONTRIBUTIONS}

ANG: Conceptualization, Data curation, Investigation, Methodology, Writing - original draft, Writing - review \& editing. MY: Conceptualization, Data curation, Investigation, Methodology, Writing - original draft, Writing - review \& editing. ANA: Investigation, Methodology, Resources, Formal Analysis, Writing - original draft, Writing - review \& editing. AKA: Data curation, Formal Analysis, Methodology, Resources, Writing - original draft.

\section{REFERENCES}

1. Herth FJ, Eberhardt R, Vilmann P, Krasnik M, Ernst A. Realtime endobronchial ultrasound guided transbronchial needle aspiration for sampling mediastinal lymph nodes. Thorax. 2006;61(9):795-8. https://doi.org/10.1136/thx.2005.047829

2. Muthu V, Gupta N, Dhooria S, Sehgal IS, Bal A, Aggarwal AN, et al. A prospective, randomized, double-blind trial comparing the diagnostic yield of 21 - and 22-gauge aspiration needles for performing endobronchial ultrasound-guided transbronchial needle aspiration in sarcoidosis. Chest. 2016;149(4):1111-3. https://doi.org/10.1016/j.chest.2016.01.014

3. Casal RF, Lazarus DR, Kuhl K, Nogueras-González G, Perusich S, Green LK, et al. Randomized trial of endobronchial ultrasoundguided transbronchial needle aspiration under general anesthesia versus moderate sedation. Am J Respir Crit Care Med. 2015;191(7):796-803. https://doi.org/10.1164/ rccm.201409-16150C

4. Lee HS, Lee GK, Lee HS, Kim MS, Lee JM, Kim HY, et al. Real-time endobronchial ultrasound-guided transbronchial needle aspiration in mediastinal staging of non-small cell lung cancer: how many aspirations per target lymph node station? Chest. 2008;134(2):368-74. https://doi.org/10.1378/ chest.07-2105

5. Ghosh A, Misra RK, Sharma SP, Singh HN, Chaturvedi AK. Aspiration vs nonaspiration technique of cytodiagnosis--a critical evaluation in 160 cases. Indian J Pathol Microbiol. 2000;43(2):107-12. PMID: 11217264 
6. Mair S, Dunbar F, Becker PJ, Du Plessis W. Fine needle cytology--is aspiration suction necessary? A study of 100 masses in various sites. Acta Cytol. 1989;33(6):809-13. PMID: 2488680

7. Boonsarngsuk V, Pongtippan A, Juthakarn S. The effect of aspiration pressure over endobronchial ultrasound-guided transbronchial needle aspiration on the diagnosis of intrathoracic lymphadenopathies. Lung. 2013;191(4):435-40. https://doi. org/10.1007/s00408-013-9480-6

8. Rodríguez F, Seijo LM, Sánchez PA, Zulueta JJ. Modified technique for obtaining mediastinal samples with endobronchial ultrasound-guided transbronchial needle aspiration: results from a prospective observational study. Arch Bronconeumol. 2013;49(4):135-9. https://doi.org/10.1016/j. arbres.2012.10.006

9. Casal RF, Staerkel GA, Ost D, Almeida FA, Uzbeck MH, Eapen GA, et al. Randomized clinical trial of endobronchial ultrasound needle biopsy with and without aspiration. Chest. 2012;142(3):568-73. https://doi.org/10.1378/chest.11-0692

10. Lin $X, Y e$ M, Li Y, Ren J, Lou Q, Li Y, et al. Randomized controlled trial to evaluate the utility of suction and inner-stylet of EBUS-TBNA for mediastinal and hilar lymphadenopathy. BMC Pulm Med. 2018;18(1):192. https://doi.org/10.1186/ s12890-018-0751-0

11. Scholten EL, Semaan R, Illei P, Mallow C, Arias S, Feller-Kopman $D$, et al. Stylet use does not improve diagnostic outcomes in endobronchial ultrasonographic transbronchial needle aspiration: a randomized clinical trial. Chest. 2017;151(3):63642. https://doi.org/10.1016/j.chest.2016.10.005

12. Paget J. Lectures on tumours, delivered in the theater of the royal college of surgeons of England. London: Longman; 1853.

13. Zajdela A, Zillhardt P, Voillemot N. Cytological diagnosis by fine needle sampling without aspiration. Cancer. 1987;59(6):1201-5. https://doi.org/10.1002/1097-0142(19870315)59:6<1201::aidcncr2820590628>3.0.c0;2-p

14. Harris K, Maroun R, Attwood K, Chalhoub M. Comparison of cytologic accuracy of endobronchial ultrasound transbronchial needle aspiration using needle suction versus no suction. Endosc Ultrasound. 2015;4(2):115-9. https://doi.org/10.4103/23039027.156737

15. Asano F, Aoe M, Ohsaki Y, Okada Y, Sasada S, Sato S, et al. Complications associated with endobronchial ultrasoundguided transbronchial needle aspiration: a nationwide survey by the Japan Society for Respiratory Endoscopy. Respir Res. 2013;14(1):50. https://doi.org/10.1186/14659921-14-50

16. Bartheld MB, Breda A, Annema JT. Complication rate of endosonography (endobronchial and endoscopic ultrasound): a systematic review. Respiration. 2014;87(4):343-51. https:// doi.org/10.1159/000357066 